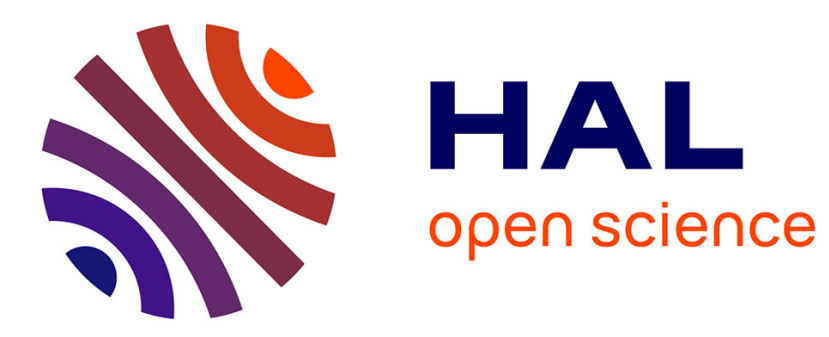

\title{
Complex conductivity of rammed earth
}

F Abdulsamad, A Revil, N Prime, P y Gnonnoue, O Plé, Myriam Schmutz

\section{To cite this version:}

F Abdulsamad, A Revil, N Prime, P y Gnonnoue, O Plé, et al.. Complex conductivity of rammed earth. Engineering Geology, 2020, 273, 10.1016/j.enggeo.2020.105697 . hal-03005830

\section{HAL Id: hal-03005830 \\ https://hal.science/hal-03005830}

Submitted on 14 Nov 2020

HAL is a multi-disciplinary open access archive for the deposit and dissemination of scientific research documents, whether they are published or not. The documents may come from teaching and research institutions in France or abroad, or from public or private research centers.
L'archive ouverte pluridisciplinaire HAL, est destinée au dépôt et à la diffusion de documents scientifiques de niveau recherche, publiés ou non, émanant des établissements d'enseignement et de recherche français ou étrangers, des laboratoires publics ou privés. 


\title{
Complex conductivity of rammed earth
}

\author{
F. Abdulsamad ${ }^{\mathrm{a}}$, A. Revil ${ }^{\mathrm{b}, *}$, N. Prime ${ }^{\mathrm{a}}$, P.Y. Gnonnoue ${ }^{\mathrm{c}}$, M. Schmutz ${ }^{\mathrm{d}}$, O. Plé ${ }^{\mathrm{a}}$ \\ ${ }^{a}$ Univ. Savoie Mont-Blanc, CNRS, UMR CNRS 5271, LOCIE, 73370 Le Bourget du Lac, France \\ ${ }^{\mathrm{b}}$ Univ. Grenoble Alpes, Univ. Savoie Mont-Blanc, CNRS, UMR CNRS 5204, EDYTEM, 73370 Le Bourget du Lac, France \\ c JFM CONSEILS, Les Ulis, France \\ ${ }^{\mathrm{d}}$ EA G\&E 4592, Bordeaux INP, University Bordeaux Montaigne, Pessac, France
}

\section{A B S T R A C T}

Searching for recyclable materials of construction, in the objective of building sobriety and resilience, is a major issue of our current societies. Mudbricks of compacted rammed earth represent an ancient construction material with many advantages associated with its availability, cost of production, potential reuse, and with a very low carbon footprint. Moisture content affects the mechanical resistance of such materials, which could become mechanically weak above a critical value. Therefore, non-intrusive characterization techniques able to image the water content distribution of these materials is highly in demand. We apply a recently developed theory of complex electrical conductivity (alias induced polarization) to characterize core samples of rammed earth materials in the laboratory. Complex conductivity describes both the ability of a porous material to conduct an electrical current (characterized by the in-phase conductivity) and its ability to store reversibly electrical charges (characterized by two interconnected properties namely the quadrature conductivity and the normalized chargeability). Samples of rammed earth and clayey soils with different pore water salinities, saturations, and compaction states are measured with the complex conductivity method in the frequency range $100 \mathrm{mHz}-45 \mathrm{kHz}$. The in-phase and quadrature conductivities of the complex conductivity of rammed earth are connected to the water content offering therefore a new non-intrusive tomographic technique to study the water content distribution in walls made of rammed earth. The data are all consistent with the so-called dynamic Stern layer model of complex conductivity for clayey materials. This new approach provides a general method to image the change in the water content of walls made of rammed earth, a task that electrical conductivity imaging cannot perform as a stand-alone technique.

\section{Introduction}

Rammed earth materials have been used by most ancient civilizations from China (including some sections of the Great Wall), to ancient Egypt (e.g., the grain store of the Ramasseum), to South America. This is because of its availability, cost, and easiness to shape and maintain (e.g., Niroumand et al., 2013). The strength of earthen constructions comes from the cohesion of dried clay. That said, when the water content of rammed earth increases, the mechanical strength of this material decreases and can be lost leading ipse facto to the erosion or the failure of the walls and the potential collapse of the construction (Bui et al., 2009a, 2009b).

In the last decade, we have seen a renewal interest for constructions in rammed earth (Miccoli et al., 2012), especially because this material presents the advantage of having a virtually zero carbon footprint. In the context of intelligent building, the development of sensor technologies (e.g., Subrt and Pechac, 2012) able to monitor, in the simplest way possible, the water content of rammed earth materials is welcome. In this study, we aim, in the present work, to develop a non-intrusive technique to get information about the moisture content of rammed earth.
Geophysical methods can provide a good solution for engineering problems in general (e.g., Panthulu et al., 2001; Rozycki et al., 2006; Himi et al., 2018). Electrical conductivity is a physical property of rocks and soils representing their ability to transport electrical charges under the influence of an electrical field. The electrical conductivity of soils and rocks is sensitive to their water content (e.g., Van Olphen and Waxman, 1958; Vinegar and Waxman, 1984). Unfortunately, electrical conductivity depends on two contributions characterized by distinct dependences on the water content. One is associated with the conduction (electro-migration of charge carriers) in the bulk pore space through the liquid pore water solution. A second contribution, called surface conductivity, is associated with conduction along the surface of the grains, more precisely in their electrical double layer (diffuse and Stern layers) coating their surface. This second contribution depends on a property known as the cation exchange capoacity (CEC) of the material. Because of the existence of these two contributions and their distinct dependence on the water content and CEC, electrical conductivity cannot be considered as a stand-alone technique (e.g., Ghorbani et al., 2018). A solution has been developed recently to cope with this issue. It is called the complex conductivity method (see for instance for soils, Revil et al., 2017a). The geophysical method

\footnotetext{
* Corresponding author.

E-mail addresses: feras.abdulsamad@univ-smb.fr (F. Abdulsamad), andre.revil@univ-smb.fr (A. Revil), noemie.prime@univ-smb.fr (N. Prime), p.gnonnoue@jfm-conseils.fr (P.Y. Gnonnoue), olivier.ple@univ-smb.fr (O. Plé).
} 


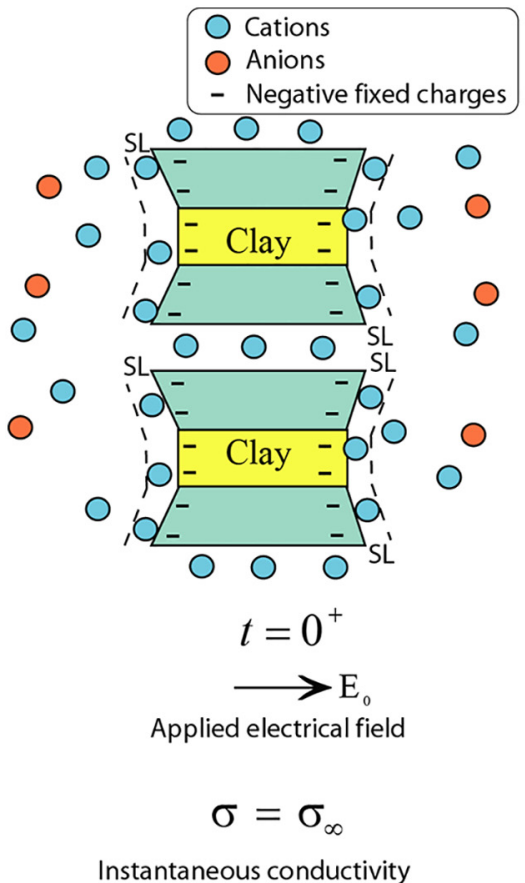

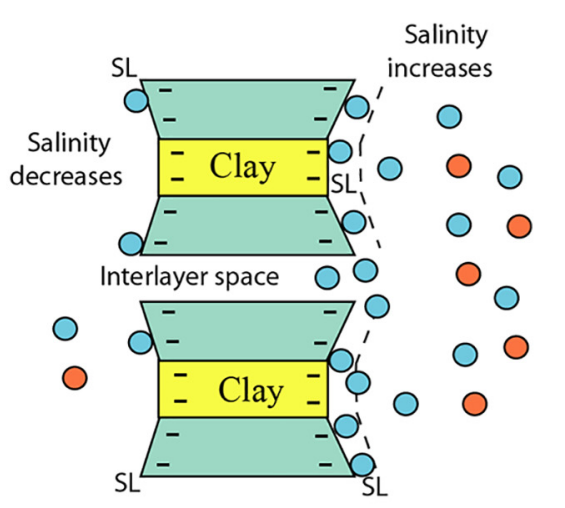

Fig. 1. Polarization of a clay particle under the action of an external (applied electrical field) $\mathbf{E}_{0}$ and implication for the electrical conductivity. a. Just after the application of $\mathbf{E}_{0}$, all the charge carriers are mobile and active in the process of electromigration. This state defines the instantaneous (or high-frequency) electrical conductivity. b. After a long application of the external electrical field, the clay gets polarized and the charges associated with this polarization do not participate any longer to the conduction process. This state defines the Direct Current (DC) conductivity. The normalized chargeability is simply the difference between the instantaneous conductivity and the DC conductivity. It characterizes the strength of the polarization process. SL stands for the Stern layer. The quantity $M$ denotes the chargeability.

$$
\begin{aligned}
& t \rightarrow+\infty \\
& \longrightarrow \mathrm{E}_{0} \\
& \text { Applied electrical field } \\
& \sigma=\sigma_{0}=\sigma_{\infty}(1-M) \\
& \text { Direct Current (DC) conductivity } \\
& \text { b. Fully polarized }
\end{aligned}
$$

associated with complex conductivity measurements is called induced polarization and its basis was initially developed by Schlumberger (1920). When measuring the electrical field associated with the passage of an electrical current through a conductive porous material, we can notice the existence of a phase lag between the current and the electrical field (Vinegar and Waxman, 1984). The conductivity amplitude (from Ohm's law) and the phase can be written in turn as a complex number called the complex conductivity (Olhoeft, 1985). This complex conductivity possesses a real (in-phase) component related to the electromigration of the charge carriers in the porous material and an imaginary (quadrature) component associated with the (non-dielectric) polarization of the material. Indeed, the porous material is able to reversibly store electrical charges. A good electrical analog of a soil or a rock is therefore an $\mathrm{RC}$ circuit where $\mathrm{R}$ is a resistance and $\mathrm{C}$ a capacitance. The complex conductivity can be measured at different frequencies and we can therefore analyze complex conductivity spectra in a certain frequency range (typically $1 \mathrm{mHz}-10 \mathrm{kHz}$ ).

Induced polarization has seen huge improvements (in both equipment precision and knowledge about the underlying physics) in last two decades (e.g., Zimmermann et al., 2008; Kemna et al., 2012; Revil et al., 2012; Schmutz et al., 2014). Initially developed for mineral exploration (e.g., Van Voorhis et al., 1973), induced polarization has then been recently used for environmental applications (Binley et al., 2005, 2015). Recent applications include the study of leakage detections in embankments and dams (Abdulsamad et al., 2019; Martínez-Moreno et al., 2018) and the study of contaminated areas (Sogade et al., 2006; Binley et al., 2015). To the best of our knowledge, induced polarization has never been used to study the water content of rammed earth materials. Such investigation is however timely since in addition to the reasons mentioned above, a recently developed theory (called the dynamic Stern layer model and based on the initial findings of Zukoski and Saville, 1986a, 1986b) is available to understand the underlying physics of complex conductivity of soils (Revil et al., 2017a) and clay rocks (Okay et al., 2013).

In this paper, we apply the complex conductivity method to characterize rammed earth core samples in the laboratory. These core samples are made from compacted mudbricks of a rammed earth used as construction material in Savoie (France). We also used a set of more porous clayey soils to compare the response of rammed earth and clayey soil response with the clayey soils having a higher porosity. This first step aims to get the petrophysical understanding required in the future to apply induced polarization tomography for the 4D imaging of the moisture content of rammed earth walls.

\section{Complex conductivity of soils}

We summarize in this section the underlying physics of complex conductivity such as developed in Revil et al. (2017a, 2017b, 2017c). We consider a porous material made of insulating mineral grains with a connected pore space partially or entirely saturated by some electrolyte (water plus ions). Typically laboratory studies are made with tap water or $\mathrm{NaCl}$ solutions. The complex conductivity of a clayey porous material is characterized by its conductivity amplitude and phase lag between a sinusoidal current injected between two current electrodes A and B and a sinusoidal electrical potential difference measured between two voltage electrodes $\mathrm{M}$ and $\mathrm{N}$. We also go from the measurement of the impedance to the measurements of the conductivity amplitude and phase thorugh a geometrical constant that depends on the position of the electrodes, the geometry of the material of interest and the bounbary conditions (see Jougnot et al., 2010). The amplitude $|\sigma|$ (in S/ m) and phase $\varphi$ (in rad) can be written as a complex-valued conductivity $\sigma^{*}(\omega)$ :

$\sigma^{*}(\omega)=|\sigma| e^{i \varphi}=\sigma^{\prime}(\omega)+i \sigma^{\prime \prime}(\omega)$

where $i$ denotes the pure imaginary number $\left(i^{2}=-1\right), \sigma$ the in-phase component (expressed in $\mathrm{S} / \mathrm{m}$ ) characterizing the ability of the material to conduct an electrical current, and $\sigma^{\prime \prime}$ (in $\mathrm{S} / \mathrm{m}$ ) the quadrature conductivity describing the ability of the material to reversibly store electrical charges (e.g., Olhoeft, 1985; Kemna et al., 2012). The ability of a soil to store electrical charges comes from the polarization of the electrical double layer coating the surface of the clay minerals (Fig. 1). The double layer is formed by a diffuse layer (called the Gouy-Chapman layer, Gouy, 1910; Chapman, 1913) and an inner layer called the Stern layer (Stern, 1924). 
The in-phase conductivity corresponds to the traditionally measured electrical conductivity. As shown by Eq. (2), it depends on two contributions, namely the bulk and surface conductivities. At a given pulsation frequency $\omega$ (expressed in $\mathrm{rad} \mathrm{s}^{-1}$ ) and in fully saturated conditions, the in-phase conductivity is related directly to the pore solution conductivity $\sigma_{w}$ and the porosity $\phi$ (dimensionless) of the porous material through the formation factor $F$ and the surface conductivity $\sigma_{s}$ (Vinegar and Waxman, 1984; Revil et al., 2017a, 2017b, 2017c):

$\sigma^{\prime}(\omega)=\frac{1}{F} \sigma_{w}+\sigma_{s}(\omega)$

Very oftern, Eq. (2) is called a Waxman and Smits type equation. In Eq. (2), the quantity $F$ (dimensionless) denotes the (electrical) formation factor, which is related to the porosity $\phi$ by a powerlaw relationship $F=\phi^{-m}$ (Archie's law, Archie, 1942). The exponent $m$ (dimensionless) is called the first Archie exponent or the porosity exponent (very often and this is rather unfortunate, the cementation exponent). The quantity $\sigma_{s}$ (in $\mathrm{S} / \mathrm{m}$ ) denotes a frequency-dependent surface (interfacial) conductivity, which varies between a low frequency asymptotic value $\sigma_{S}{ }^{0}$ (Direct Current DC surface conductivity) and a highfrequency asymptotic value $\sigma_{S}{ }^{\infty}$ called the instantaneous surface conductivity. This surface conductivity takes place in the electrical double layer coating the surface of the grains (Fig. 1) and comprises two contributions: one from the diffuse layer (frequency independent and corresponding to $\sigma_{S}{ }^{0}$ ) and one from the Stern layer (which is frequency dependent and corresponding to the difference $\sigma_{S}{ }^{\infty}-\sigma_{S}{ }^{0}$, see Figs. 1 and 2).

In order to interpret complex conductivity spectra in a metal-free partially-saturated porous material, we need to describe a fundamental model called the dynamic Stern layer model (e.g., Revil, 2013a, 2013b, Fig. 1). An electric field $\mathbf{E}=\mathbf{E}_{0} \exp (+i \omega t)$ ( $t$ is time) is applied to the porous material. The complex conductivity is written as (Revil et al., 2017a)

$$
\sigma *(\omega)=\sigma_{\infty}-M_{n} \int_{0}^{\infty} \frac{h(\tau)}{1+(i \omega \tau)^{1 / 2}} d \tau+i \omega \varepsilon_{\infty}
$$

The quantity $\varepsilon_{\infty}$ denotes the permittivity of the material (in $\mathrm{F} \mathrm{m}^{-1}$ ), $\tau$ is a relaxation time (in s), and $h(\tau)$ denotes a (normalized) probability density for distribution of the time constants of the porous media. The quantity $\sigma_{\infty}(\mathrm{S} / \mathrm{m})$ defined the instantaneous conductivity of the material. In time-domain induced polarization, this corresponds to the measured conductivity just after the application of the external (primary or applied) electrical field (Fig. 1). The quantity $\sigma_{0}(\mathrm{~S} / \mathrm{m})$ defined the DC (Direct Current) conductivity of the porous material obtained by measuring the conductivity when the electrical field has been applied for a long time (Fig. 1). By "long time", we mean that all the polarization lengths scales (typically all the grains) are fully polarized. It should be noticed that polarizing a big grain takes always more time than polarizing a small grain. From these considerations, the DC conductivity is necessarily smaller than the instantaneous conductivity since the charges responsible for the polarization are not available anymore for the conduction process (Fig. 2a and b). This can be generalized by stating that conductivity necessarily increases with the frequency between two limiting values. We will come back later to the measurement principle, but the complex conductivity is measured thanks to an impedancemeter such as shown in Fig. 3. A last note about Eq. (3) is that in the present paper, we are not interested by the distribution of time constants (relaxation times) $h(\tau)$, which could be related to the pore size or grain size distributions.

The last ingredient of Eq. (3) is the normalized chargeability $M_{n}$. It corresponds to the difference between the the instantaneous conductivity and the DC conductivity (or let say the conductivity values at high and low frequencies)

$M_{n} \equiv \sigma_{\infty}-\sigma_{0}$

We consider now that the porous material is partially saturated with the pore water electrolyte and $s_{w}$ (dimensionless) denotes the water a. Complex conductivity spectrum
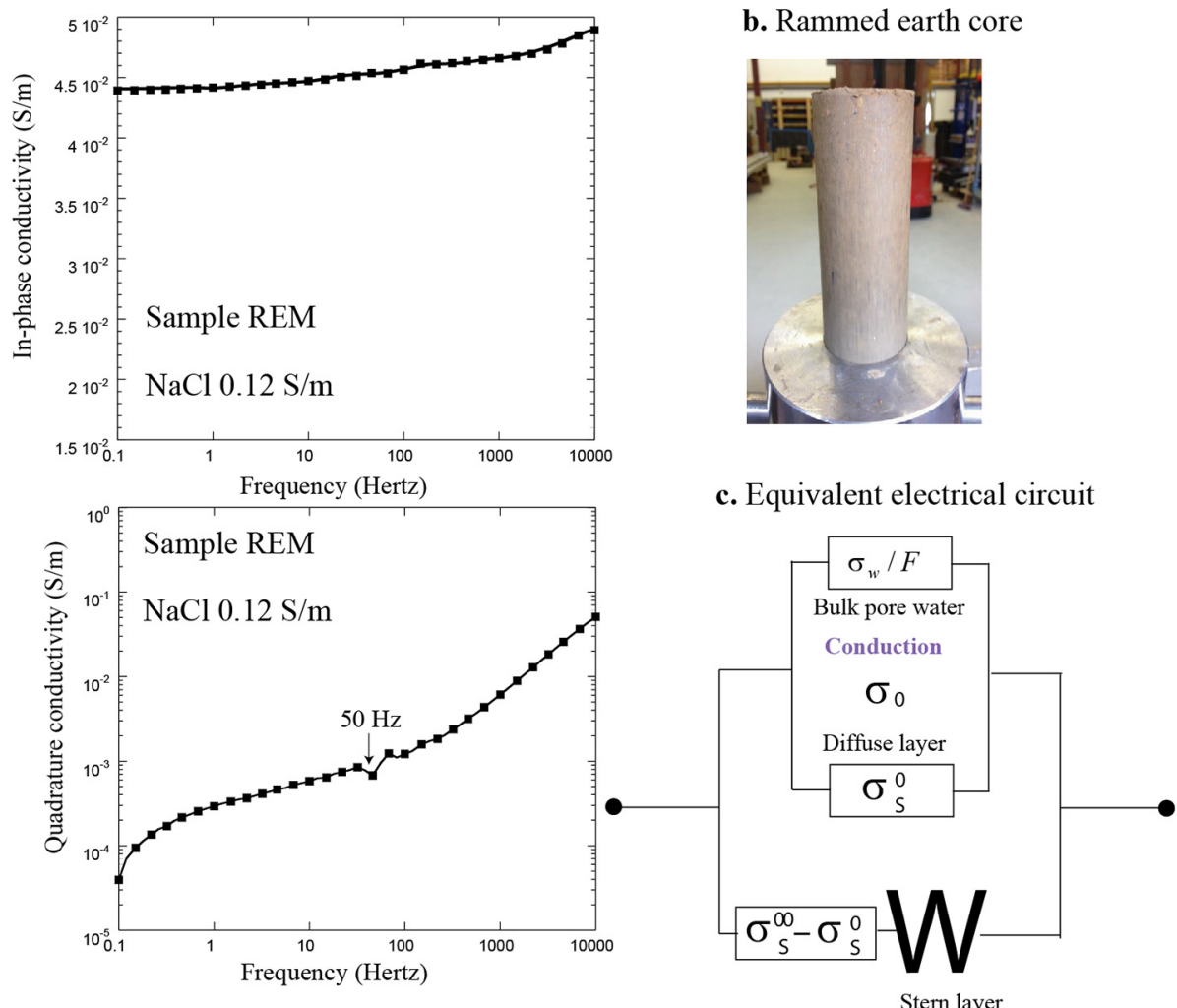

Fig. 2. Complex conductivity of a rammed earth or a soil. a. In phase conductivity and quadrature conductivity spectra. b. Example of compacted core sample. c. Equivalent circuit for a rammed earth. The W denotes a Warburg-type capacitance, which explains the dependence of Eq. (3) with the frequency (see Revil et al., 2017a). Conduction through the rammed earth comprises two contributions, one associated with the bulk pore water and the other with conduction in the electrical double layer (surface conductivity). The quantities $\sigma_{S}{ }^{\infty}$ and $\sigma_{S}{ }^{0}$ represent the instantaneous and DC surface conductivity, respectively. They correspond to the last terms of Eqs. (8) and (9), respectively. 


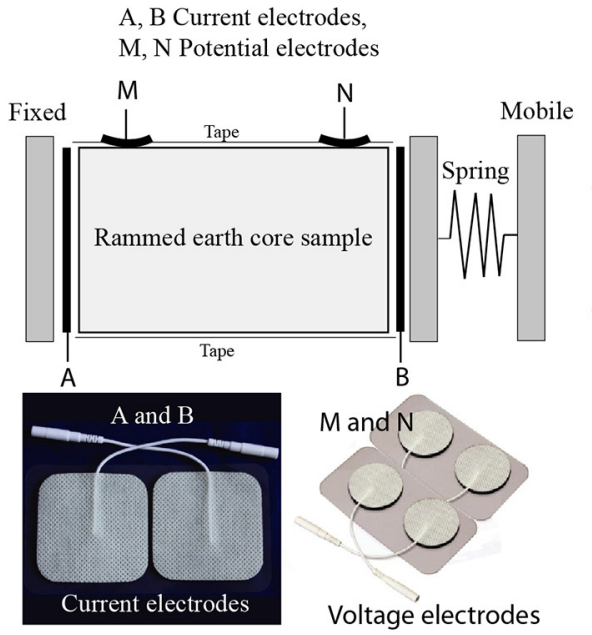

a. Complex conductivity cell

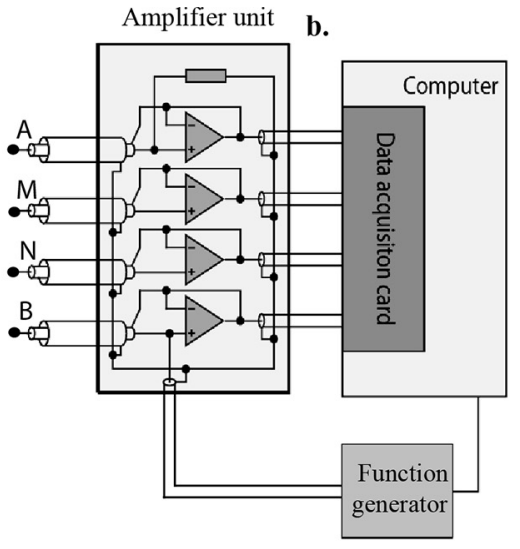

b. ZEL-SIP04-V02
Fig. 3. Complex conductivity measurements of rammed earth and soils. a. Sketch of the experimental setup. The electrodes are self-adhesive super conductive carbon film with biocompatible hydrogel. b. The ZEL-SIP04-V02 impedance meter is used for the laboratory experiments (see Zimmermann et al., 2008, for details). This impedancemeter works in the frequency range $1 \mathrm{mHz}-45 \mathrm{kHz}$. saturation related to the (volumetric) water content $\theta$ by $\theta=s_{w} \phi\left(s_{w}=\right.$ 1 corresponds to full saturation). Using the petrophysical model developed by Revil (2013a, 2013b), we obtain the following explicit dependencies of the high- and low-frequency conductivities and normalized chargeability:

$\sigma_{\infty}=\frac{s_{w}^{n}}{F} \sigma_{w}+\left(\frac{s_{w}^{n-1}}{F \phi}\right) \rho_{g} B \mathrm{CEC}$

$\sigma_{0}=\frac{s_{w}^{n}}{F} \sigma_{w}+\left(\frac{s_{w}^{n-1}}{F \phi}\right) \rho_{g}(B-\lambda) \mathrm{CEC}$

$M_{n}=\left(\frac{s_{w}^{n-1}}{F \phi}\right) \rho_{g} \lambda \mathrm{CEC}$

In these equations $n$ (dimensionless) denotes the saturation exponent (dimensionless) and typically $m \approx n$ (Revil, 2013b), $\rho_{g}$ denotes the grain density (in $\mathrm{kg} \mathrm{m}^{-3}$ ), which is related to the dry density by $\rho_{d r y}=(1-\phi) \rho_{g}$, and CEC denotes the cation exchange capacity of the material (Aran et al., 2008). It is expressed in $\mathrm{C} \mathrm{kg}^{-1}$ or in meq/100 $\mathrm{g}$ with $1 \mathrm{meq} / 100 \mathrm{~g}=963.20 \mathrm{C} \mathrm{kg}^{-1}$. This cation exchange capacity corresponds to the density of exchangeable surface sites on the surface of the mineral grains. It is typically measured using titration experiments in which the surface of the grains is exchanged with a cation having a high affinity for the sites populating the mineral surface. The CEC is mainly sensitive to the clay type (e. g., kaolinite, illite or smectite, see Fig. 4) and the weight fraction of these clay minerals in the clayey soils. In Eqs. (5) and (6), $B$ (in $\mathrm{m}^{2} \mathrm{~s}^{-1} \mathrm{~V}^{-1}$ ) denotes the apparent mobility of the counterions for surface conduction and $\lambda$ (in $\mathrm{m}^{2} \mathrm{~s}^{-1} \mathrm{~V}^{-1}$ ) denotes the apparent mobility of the counterions for the polarization associated with the quadrature conductivity. A dimensionless number $R$ has been introduced by Revil et al. (2017a) $\mathrm{R}=\lambda / B$. From previous studies (e.g., Ghorbani et al., 2018), we have $B\left(\mathrm{Na}^{+}, 25{ }^{\circ} \mathrm{C}\right)=3.1 \pm 0.3 \times 10^{-9} \mathrm{~m}^{-2} \mathrm{~s}^{-1} \mathrm{~V}^{-1}$ and $\lambda\left(\mathrm{Na}^{+}, 2{ }^{\circ} \mathrm{C}\right)$ $=3.0 \pm 0.7 \times 10^{-10} \mathrm{~m}^{-2} \mathrm{~s}^{-1} \mathrm{~V}^{-1}$, and $R \approx 0.09 \pm 0.01$ (Ghorbani et al., 2018). The last terms of Eqs. (5) and (6) correspond exactly to the terms $\sigma_{S}{ }^{\infty}$ and $\sigma_{S}{ }^{0}$, respectively.

Assuming $m=n$, we can rewrite in a simplified way Eqs. (5) to (7) directly as a function of the water content as

$\sigma_{\infty}=\theta^{m} \sigma_{w}+\theta^{m-1} \rho_{g} B$ CEC

$\sigma_{0}=\theta^{m} \sigma_{w}+\theta^{m-1} \rho_{g}(B-\lambda) \mathrm{CEC}$

$M_{n}=\theta^{m-1} \rho_{g} \lambda \mathrm{CEC}$

As mentioned in the introduction, we see that the conductivity of a

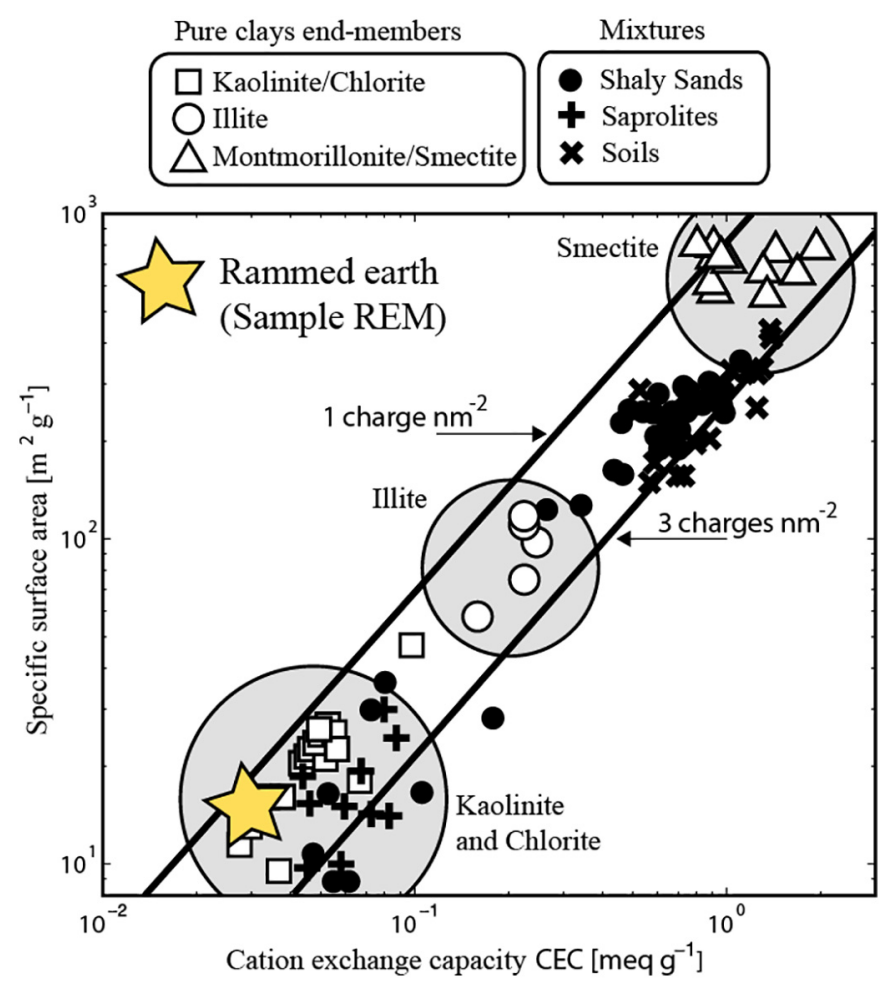

Fig. 4. Specific surface area versus cation exchange capacity (expressed in meq $\mathrm{g}^{-1}$ with 1 meq $\mathrm{g}^{-1}=96,320 \mathrm{C} \mathrm{kg}^{-1}$ ). The two lines correspond to a surface charge density of 1 to 3 elementary charges per unit surface area. The rammed earth (sample REM) corresponds to a low CEC clayey soil.

porous material $\left(\sigma_{\infty}\right.$ or $\sigma_{0}$ ) has two contribution with distinct dependence on the water content $\theta$.

The normalized chargeability and the quadrature conductivity are interrelated especially when the spectra are relatively flat as this is the case for soils (see Appendix A in Revil et al., 2017a). Considering the quadrature conductivity at the geometric mean frequency of two frequencies $f_{1}$ and $f_{2}$ and the normalized chargeability defined as the difference between the in-phase conductivity at the frequency $f_{2}\left(>f_{1}\right)$ and the in-phase conductivity at the lower frequency $f_{1}$, we have (Van Voorhis et al., 1973; Revil et al., 2017a)

$\sigma^{\prime \prime}\left(\sqrt{f_{1} f_{2}}\right) \approx-\frac{M_{n}\left(f_{1}, f_{2}\right)}{\alpha}$ 
$\alpha \approx \frac{2}{\pi} \ln A$

and $A$ denotes the number of decades between $f_{1}$ and $f_{2}$ (for 3 decades, we have $A=10^{3}$ and $\alpha \approx 4$.4). We can now easily draw a relationship between the quadrature conductivity and the surface conductivity as

$-\frac{\sigma^{\prime \prime}}{\sigma_{S}}=\frac{M_{n}}{\alpha \sigma_{S}}=\frac{R}{\alpha}$

Eq. (11) to (13) close the set of equations needed to understand induced polarization of rammed earth. In the next section, we test the relationships summarized in this section with respect to new measurements on rammed earth and soils.

\section{Materials and methods}

\subsection{Core samples}

The material labeled REM (rammed earth material) used in this study was obtained from an existing construction site in the Auvergne Rhône Alpes region in France. Material from this site was traditionnaly used for rammed earth structures in this region. The analysis of the particle size distribution shows that the material contains $40 \%$ sand, $53 \%$ silt, and $7 \%$ clay. Previous studies were performed on this rammed earth material to determine the optimum water content insuring getting the maximum dry density and the optimum compaction pressure associated the highest mechanical resistance of the material. Using the standard proctor test, the optimum water content was found to be about $12.5 \%$ (weight water content) for a static compaction at $5 \mathrm{MPa}$. The maximum dry density reached is $1900 \mathrm{~kg} \mathrm{~m}^{-3}$.

For our study, 20 REM samples were prepared using the same soil. First, the earth was prepared at the optimum water content discussed above and placed in an air-tight container for moisture homogenization. Then, the partially saturated material was put in a cylindrical mold of $5 \mathrm{~cm}$ diameter and $10 \mathrm{~cm}$ height. Later, the mold was subjected to a compaction pressure ( $5 \mathrm{MPa}$ ). In order to get homogeneous density in the samples, $80 \%$ of the total compaction pressure, i.e., $4 \mathrm{MPa}$ was applied gradually from one side, and then $100 \%$ of the total compaction pressure, i.e., $5 \mathrm{MPa}$ was applied from both sides, according to the methodology proposed by Bruno et al. (2016). For more information about soil and sample preparation see Chauhan et al. (2019).

In addition to REM, soil samples were used to investigate the effect of clayey soil properties on the complex conductivity spectra. A collection of 18 additional clayey soil samples was added to the REM dataset to see the effect of having clayey samples with a higher porosity (see Table 1). A total of 18 soil samples were extracted from a vineyard located in Pessac-Leognan near Bordeaux (Gironde, France). The plot location is denominated by colluviosol (Baize and Girard, 1998) characterized by 6 horizons: from 0 to $0.4 \mathrm{~m}$ (horizon 1), from 0.4 to $1 \mathrm{~m}$ (horizon 2) and from $1 \mathrm{~m}$ to $1.25 \mathrm{~m}$ (horizon 3), from 1.25 to $1.45 \mathrm{~m}$ (horizon 4), from 1.45 to $1.75 \mathrm{~m}$ (horizon 5), and from 1.75 to $2.1 \mathrm{~m}$ (horizon 6). Our samples are distributed into horizons 1 and 2. All horizons contain high content of fine sand $(20 \mu \mathrm{m}$ to $200 \mu \mathrm{m})$ ranging from 30 to $54 \%$, horizon 1 to 4 contain significant coarse sand $(0.2$ to $2 \mathrm{~mm}$ ) ranging from 20 to $42 \%$ ). Horizons 1 to 3 contain organic matter (from 0.13 to $0.7 \%$ ). Horizon 1 is characterized by $20 \%$ of coarse elements ( $>2 \mathrm{~mm}$ grain size diameter), and about $35 \%$ of coarse and fine sands, respectively. Organic matter is about $0.7 \%$ and $\mathrm{pH}$ equal to 6.7 . Horizon 2 has got the same physical characteristics than horizon 1 in terms of granulometric classes with a slightly higher content of coarse sand $(42 \%)$. Organic matter is very low $(0.13 \%)$ and $\mathrm{pH}$ is equal to 7.8 . Textural analysis of the core samples indicate a clay content comprised between 2 and $20 \%$ ( $\%$ vol.).
Table 1

Petrophysical properties of the core samples. The quadrature conductivity is reported at $32 \mathrm{~Hz}$ (samples E1 to E19, pore water conductivity of $0.072 \mathrm{~S} / \mathrm{m}$ at $25{ }^{\circ} \mathrm{C}, \mathrm{NaCl}$, sample REM pore water conductivity of $0.12 \mathrm{~S} / \mathrm{m}$ at $25^{\circ} \mathrm{C}, \mathrm{NaCl}$ ). The normalized chargeability reported in the table is determined at the lowest salinity and between $1 \mathrm{~Hz}$ and $1 \mathrm{kHz}$.

\begin{tabular}{|c|c|c|c|c|c|c|c|}
\hline Core ID & $\phi(-)$ & $\begin{array}{l}\text { CEC } \\
\text { (meq/ } \\
100 \mathrm{~g} \text { ) }\end{array}$ & $F(-)$ & $\sigma_{\mathrm{S}}(\mathrm{S} / \mathrm{m})$ & $M_{n}(\mathrm{~S} / \mathrm{m})$ & $\sigma "(\mathrm{~S} / \mathrm{m})$ & $\begin{array}{l}\text { Main } \\
\text { grain size } \\
(\mu \mathrm{m})\end{array}$ \\
\hline E1 & 0.35 & 11.9 & 5.55 & 0.0584 & 0.0049 & 0.0010 & 105 \\
\hline E2 & 0.36 & 9.53 & 7.89 & 0.0711 & 0.0026 & 0.0006 & 98 \\
\hline E3 & 0.36 & 7.21 & 4.80 & 0.0402 & 0.0010 & 0.0003 & 63 \\
\hline E4 & 0.39 & 16.1 & 8.56 & 0.115 & 0.0054 & 0.0013 & 88 \\
\hline E5 & 0.44 & 16.6 & 7.39 & 0.14 & 0.0036 & 0.0008 & 40 \\
\hline E6 & 0.41 & 15.5 & 6.68 & 0.112 & 0.0055 & 0.0012 & 40 \\
\hline E7 & 0.39 & 7.82 & 4.06 & 0.0673 & 0.0034 & 0.0007 & 4 \\
\hline E8 & 0.43 & 7.24 & 3.42 & 0.0264 & 0.0021 & 0.0005 & 8 \\
\hline E9 & 0.42 & 11.5 & 3.97 & 0.0352 & 0.0025 & 0.0002 & 101 \\
\hline E10 & 0.43 & 7.67 & 6.81 & 0.0969 & 0.0027 & 0.0006 & 8 \\
\hline E11 & 0.40 & 7.3 & 5.03 & 0.07 & 0.0021 & 0.0005 & 100 \\
\hline E12 & 0.51 & 20 & 6.48 & 0.175 & 0.0090 & 0.0021 & 40 \\
\hline E13 & 0.52 & 19.9 & 3.35 & 0.0968 & 0.0036 & 0.0014 & 125 \\
\hline E14 & 0.44 & 15.8 & 5.90 & 0.127 & 0.0054 & 0.0012 & 125 \\
\hline E15 & 0.43 & 9.77 & 6.77 & 0.157 & 0.0062 & 0.0019 & 125 \\
\hline E17 & 0.48 & 17.9 & 3.69 & 0.242 & 0.0147 & 0.0041 & 75 \\
\hline E18 & 0.45 & 12.3 & 7.37 & 0.189 & 0.0073 & 0.0017 & 93 \\
\hline E19 & 0.44 & 11.5 & 3.22 & 0.022 & 0.0003 & 0.0004 & 125 \\
\hline REM & 0.26 & 2.6 & 9.10 & 0.031 & 0.00024 & 0.00085 & - \\
\hline
\end{tabular}

\subsection{Petrophysical measurements}

In order to get more information about REM, we performed some petrophysical measurements. The permeability of the REM sample is $\sim 3 \times 10^{-16} \mathrm{~m}^{2}(\sim 0.3 \mathrm{mD})$. The porosity of the core samples was estimated and the values are reported in Table 1 . Furthermore, the dry density $\left(\rho_{g}\right)$, the cation exchange capacity (CEC) and specific surface area $\left(S_{s p}\right)$ were also estimated for the rammed earth. The cation exchange capacity measured with the cobalthexamine method (Aran et al., 2008; Ciesielski et al., 1997) was $2.6 \mathrm{meq} / 100 \mathrm{~g}$ for the rammed earth. The measurement of the specific surface area was carried out with the BET method, using nitrogen as adsorbent gas. The low values of CEC and $S_{s p}\left(2.6 \mathrm{meq} / 100 \mathrm{~g}\right.$ and $14.7 \mathrm{~m}^{2} / \mathrm{g}$, respectively) suggest a very low percentage or absence of swelling clays (Fig. 4). Table 1 shows the petrophysical characteristic of the samples prepared and tested in this study.

\subsection{Complex conductivity measurements}

Frequency-domain induced polarization measurements were performed over the frequency range from $100 \mathrm{mHz}$ to $45 \mathrm{kHz}$ using the ZELSIP04-V02 impedance meter (Zimmermann et al., 2008) in Julich (Germany). The impedance meter and the sample holder are shown in Fig. 3. The electrical current was injected between two electrodes (A and B) at the end faces of the sample, while the electrical potential was measured between two other electrodes ( $\mathrm{M}$ and $\mathrm{N}$ ) on the side of the sample.). For our experiments, we used a constant voltage of $10 \mathrm{~V}$ across the samples. The recorded phase was typically below $50 \mathrm{mrad}$ and in most of the cases smaller than 10 mrad implying very good precisions in the measurements. We estimated an error on the phase of 0.1-0.2 mrad based on measurement reproductibility. At each frequency, we used 6 stacks and we use 5 measurements per frequency decade and 3 cycles per measurement. Medical electrodes have been used for the current injection and potential measurements with a conductive gel to ensure a good contact. The amplitude of the complex conductivity and the phase shift between the injected current and the measured potential were recorded. The conversion of the measured impedance into the complex conductivity was performed using a geometric factor $K\left(\mathrm{~m}^{-1}\right)$ depending on the position of the electrodes. The 
geometric factor was estimated by numerical modelling using the software COMSOL Multiphysics (see Jougnot et al., 2010).

In order to characterize the rammed earth used in his study, we performed 3 types of experiments. First, 6 samples of rammed earth (REM for Rammed Earth Material) were prepared at the same condition of compaction (to get the same texture and porosity of the samples). Then, the samples were saturated with an electrolyte $(\mathrm{NaCl})$ at different pore water electrical conductivity $\sigma_{w}\left(\sigma_{w}\right.$ equal to $0.03,0.10,0.12,0.54$, 1.05 , and $10.8 \mathrm{~S} / \mathrm{m}$ at $25^{\circ} \mathrm{C}$ ). The saturation performed under vacuum and the samples were kept for one week in the solution. Before saturation we put the samples in a tube to prevent them collapsing. In addition, 8 other REM samples prepared with the same conditions (compaction pressure, water content and water conductivity) then each sample was put in a controlled humidity box (at a constant relative humidity) for about 6 weeks to get different saturation levels. Each saturation level was controlled by different salts, which control the relative humidity of the air around the core sample by liquid-vapor equilibrium. 7 relative humidities (HR) were applied with different salts used to control this relative humidity ( $\mathrm{KOH}, 9 \% \mathrm{HR} ; \mathrm{CH}_{3} \mathrm{CO}_{2} \mathrm{~K}, 22.5 \%$ $\mathrm{HR}$; $\mathrm{MgCl}_{2}, 32 ; 8 \%$; $\mathrm{NaBr} 57.6 \% \mathrm{HR}$; $\mathrm{NaCl} 75.3 \% \mathrm{HR}$; KCl 84.34\% HR; $\mathrm{K}_{2} \mathrm{SO}_{4} 97.3 \% \mathrm{HR}$ ). During this period the weight of the samples was taken until getting the equilibrium state (i.e., no change in the sample weight), at which complex conductivity measurements could be performed. Finally, the effect of compaction pressure on the electrical response was evaluated. 3 samples were prepared at different compaction pressures (2, 4 and $7 \mathrm{MPa}$ ) and using the same water content and water conductivity. Typical spectra are shown in Figs. 2 and 5.

\section{Results}

\subsection{Influence of compaction pressure}

Three samples were prepared with different compaction pressures (at 2, 4, and $7 \mathrm{MPa}$ ), and saturated with water solution of conductivity $0.067 \mathrm{~S} / \mathrm{m}$. Fig. 5 shows the in-phase and quadrature conductivity as a function of frequency at the three compaction pressures. We could notice a slight influence of the compaction pressure on the electrical response. However, this influence might come from the fact that the saturation level change with compaction pressure. Porosity decreases

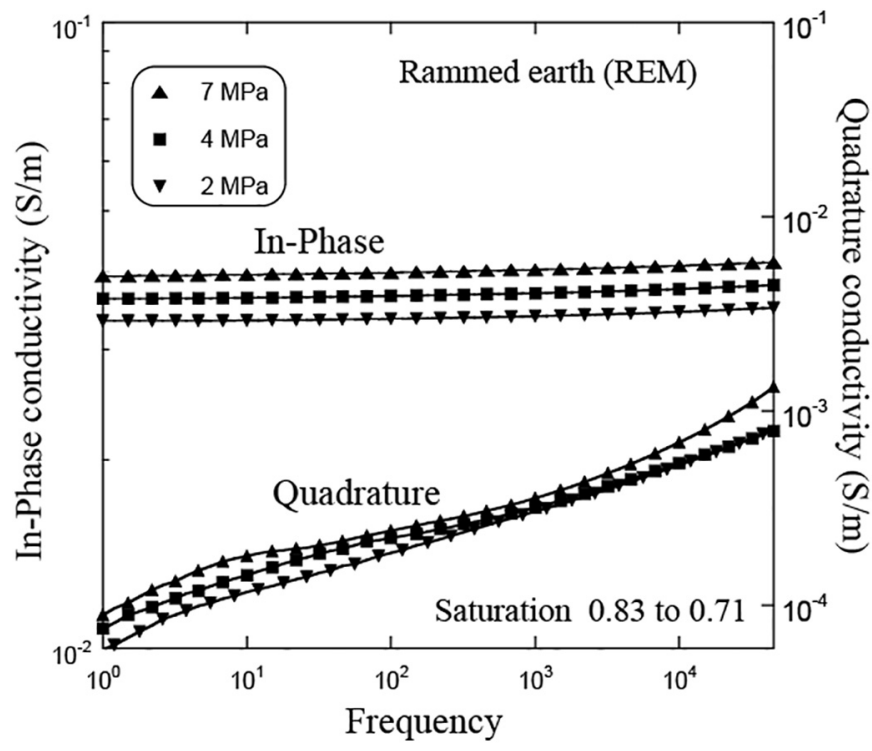

Fig. 5. Typical complex conductivity spectra of rammed earth at different compaction uniaxial pressures $(2,4,7 \mathrm{MPa})$. The samples are not completely saturated in these experiments $(12.5 \%$ as gravimetric water content) so the saturation increases with the degree of compaction explaining the increase of both the in-phase and quadrature conductivity with the confining pressure.

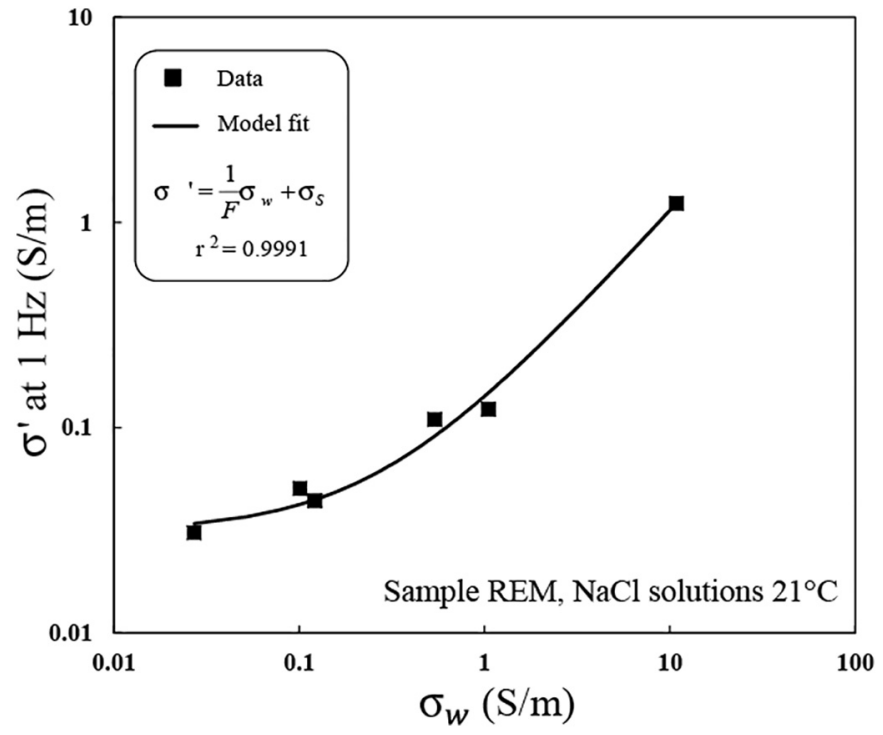

Fig. 6. In-phase conductivity $(1 \mathrm{~Hz})$ versus pore water conductivity $\sigma_{w}$. The measurements are here made at full saturation with the core sample REM. The fit with a linear conductivity model (Eq. 2) yields the value of the formation factor $F$ and the surface conductivity $\sigma_{S}$, which are reported in Table 1 . We see that at low salinities, the conductivity of the material is quickly dominated by its surface conductivity, which is in turn controlled by its cation exchange capacity at saturation.

with increasing compaction pressure, while the gravimetric water content is always the same $(21.5 \%)$ that says the saturation increases with compaction, which explains the increase in the conductivity. On the other hand, the influence of the compaction pressure on the normalized chargeability (calculated between $1 \mathrm{~Hz}$ and $10 \mathrm{kHz}$ ) is less pronounced.

\subsection{Influence of the pore water salinity}

The spectral response of the samples fully saturated by different salinities (it electrical conductivity equal to $\sigma_{w}=0.03,0.10,0.12,0.54$, 1.05 , and $10.8 \mathrm{~S} / \mathrm{m}$ at $25{ }^{\circ} \mathrm{C}$ ) was measured for the rammed earth. The dependence of the in-phase conductivity with the pore water conductivity (see Fig. 6) provides information about the formation factor and surface conductivity by fitting the data with Eq. (2). This work is done for boh the rammed earth and the soil samples and the formation factors and surface conductivity are reported in Table 1. In Fig. 6, we observe that for low pore water salinities (typically below $10^{-2} \mathrm{Mol}$ $\mathrm{L}^{-1}$ equivalent $\mathrm{NaCl}$ ), the (in-phase) conductivity of the rammed earth is dominated by the surface conductivity because of the presence of the clay particles. This situation will be typical of walls made in rammed earth materials. So understanding how surface conductivity depends on the texture of the material (porosity and cation exchange capacity) and environmental variables such as the water content is very important to achieve a good understanding of induced polarization in civil engineering.

\subsection{Testing few useful relationships}

In Fig. 7, we plot the formation factor versus the (connected) porosity. The data set is fitted with an Archie's law $F=\phi^{-m}$ for the full set of samples, a typical value for low clayey soilk (Revil et al., 2017a). We notice that the cementation exponent of rammed earth and soils is about $m \approx 1.64$. The second point, we want to test is the relationship between the quadrature conductivity and the surface conductivity. Both the quadrature and surface conductivity are related to the electrical double layer and according to the dynamic Stern layer model their ratio 


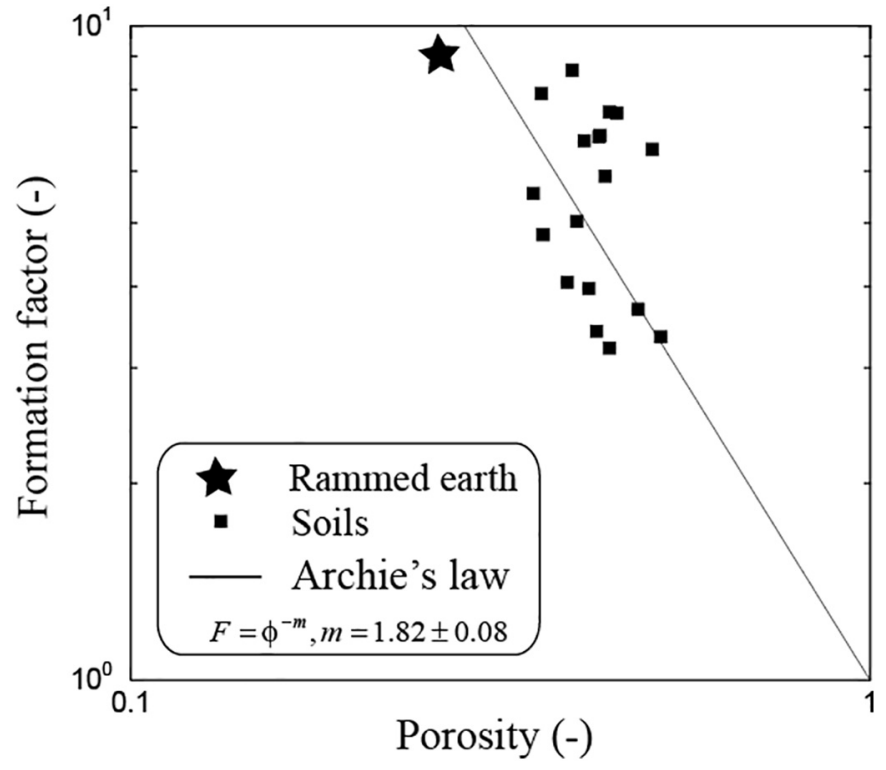

Fig. 7. Fit of Archie's law between the formation factor $F$ and the (connected) porosity $\phi$. The fit is used to obtain an average value of the cementation (porosity) exponent $m$. The rammed earth has a larger formation factor with respect to the soils because of its lower porosity due to compaction.

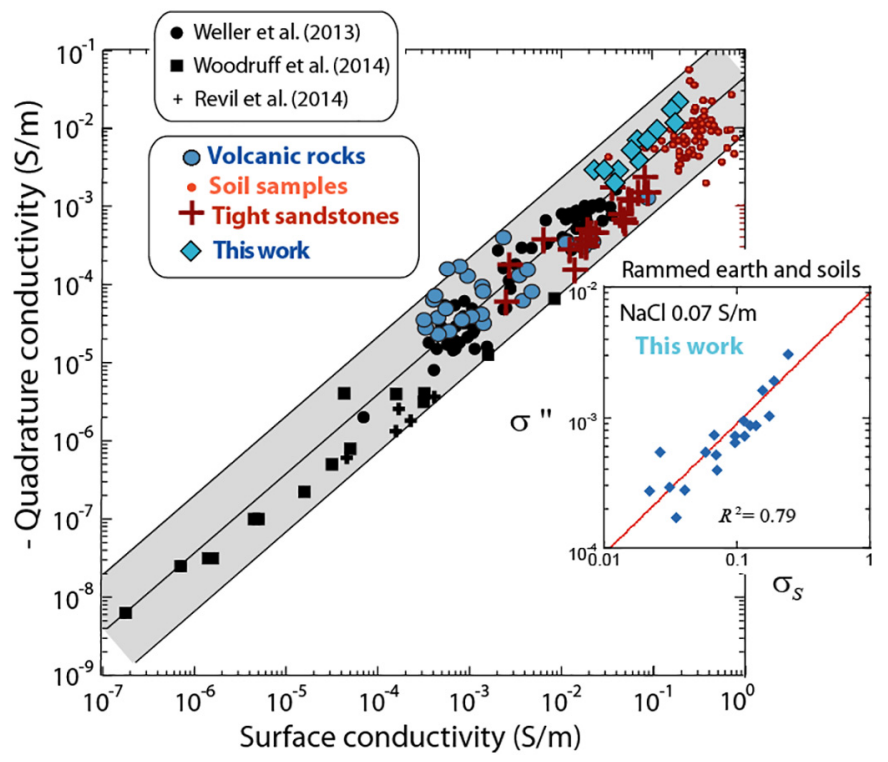

Fig. 8. Relationship between quadrature conductivity and surface conductivity over seven orders of magnitude. Soil samples from Revil et al. (2017a), volcanic rocks from Revil et al. (2017b, 2017c). Other data from Weller et al. (2013) (sands and sandstones), Woodruff et al. (2014) (oil and gas shales), and Revil et al. (2014) (Fontainebleau sandstones). For the core samples investigated here (see insert), we obtain $-\sigma \gg / \sigma_{S}=0.0090 \pm 0.0006$. Using $R=-\alpha \sigma^{\prime \prime} / \sigma_{S}$ and $\alpha=9$ we obtain $R=0.08$, which is consistent with the value discussed in Section 2. According to the dynamic Stern layer model, this trend is independent of the value of the formation factor and the porosity of the core samples.

can be determined by Eq. (13). This linear relationship is confirmed by the trend shown in Fig. 8. The third relationship to test is the relationship between the normalized chargeability (measured by the difference of the in-phase conductivity at two frequencies) and the quadrature conductivity at the geometric mean frequency (see Eqs. 11 and 12). As shown in Fig. 9, this linear relationship is also confirmed by the experimental data.

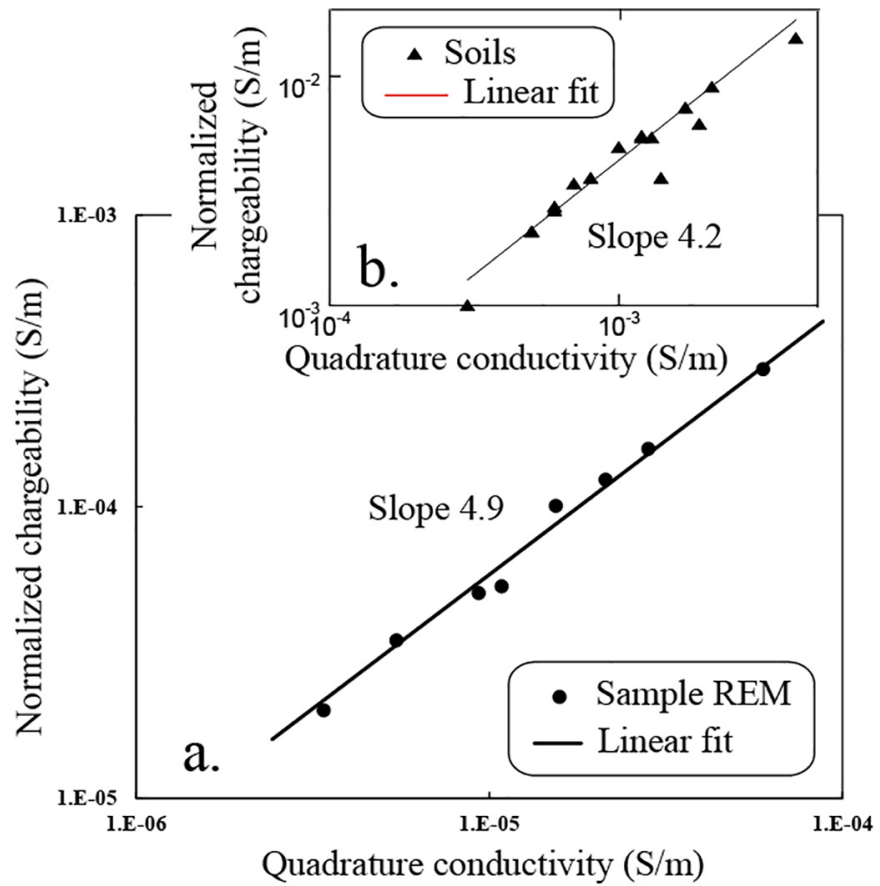

Fig. 9. Relationship between the normalized chargeability (between the frequencies $1 \mathrm{~Hz}$ and $1 \mathrm{kHz}$ ) and the quadrature conductivity at the geometric frequency of $32 \mathrm{~Hz}$. Different water saturations. b. Soil samples at full water saturation. a. REM Samples at different saturations. The slope $\alpha$ is found to be 4.9 for the REM samples and 4.3 for the soils while the theory (Eqs. (11) and (12)) predicts a slope of 4.3. If the normalized chargeability would be determined over 6 orders of magnitude, we would expect to have $\alpha=9$, which is the value used in Fig. 8.

\subsection{Effect of the cation exchange capacity}

Figs. 10 and 11 shows that the samples used in this study are consistent with other datasets made on porous rocks. The surface conductivity and quadrature conductivity are both linearly proportional to the cation exchange capacity of the material. The dependence of the quadrature conductivity with the CEC is derived right away by combining Eqs. (10) and (11). The dependence of the surface conductivity with the CEC is from the last term of Eqs. (8) and (9). Therefore, Figs. 8 to 11 indicates that we have form a unified theory of induced polarization in which both the conductivity and the normalized chargeability can be derived in a unified framework, which is validated by experimental data.

\subsection{Influence of water content}

In order to test the dependence of the in-phase conductivity and quadrature conductivity with the water content, we extracted the inphase and quadrature components of the complex conductivity at $1 \mathrm{kHz}$. This frequency is justified by the fact that the clay mineral would polarize at quite high frequencies because of their small particle sizes. In Fig. 12, we plot both the in-phase and quadrature conductivity versus the water saturation. When the conductivity is dominated by the bulk contribution, its dependence with the water content is $\sigma^{\prime} \sim \theta^{m}$ while the quadrature conductivity is expected to depend on the water content as $\sigma^{\prime \prime} \sim M_{n} \sim \theta^{m-1}$. The data are consistent with $m=2.1$. This dependence can be used to assess the effect of the water content on the complex conductivity and in turn to use induced polarization tomography to image the fluctuations of the water content over space and time. 


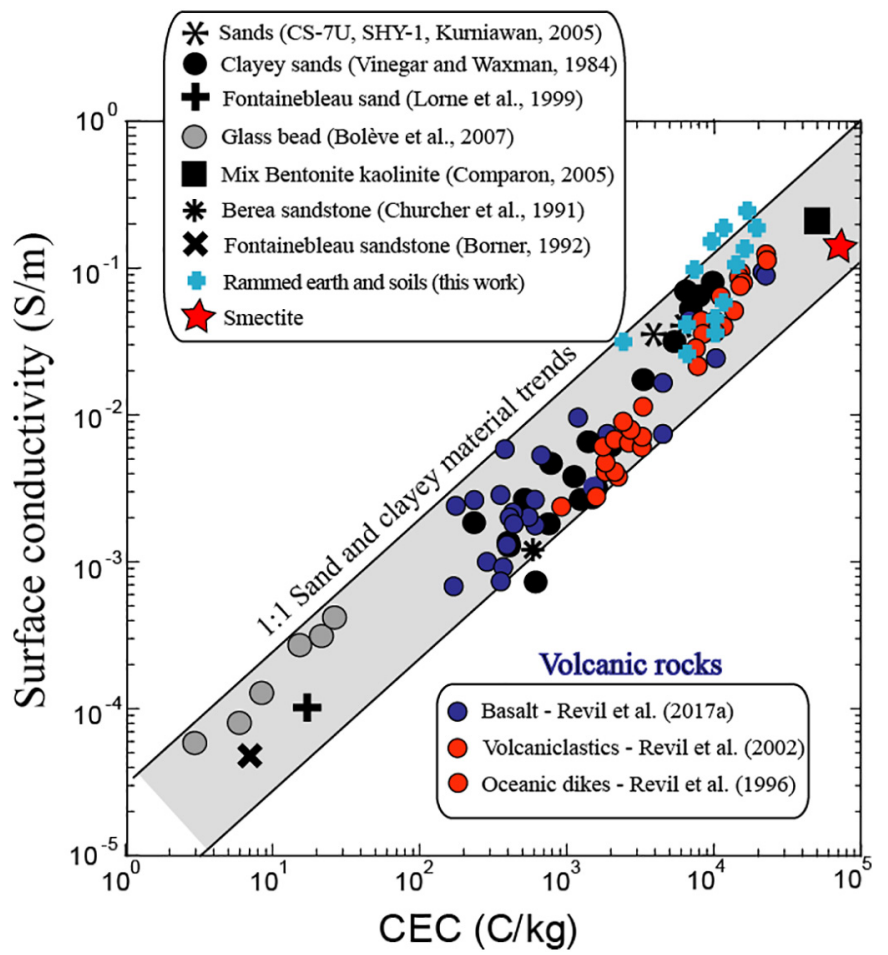

Fig. 10. Surface conductivity versus cation exchange capacity (CEC). The data from the literature are from Bolève et al. (2007, glass beads, $\mathrm{NaCl}$ ), Vinegar and Waxman (1984, shaly sands, $\mathrm{NaCl}$ ), Churcher et al. (1991) (CEC for the Berea sandstone), Lorne et al. (1999, Fontainebleau sand KCl), Kurniawan (2005, clean sand, Sample CS-7U), Börner (1992, sample F3 Fontainebleau sandstone), and Comparon (2005, mixtures of MX80 bentonite and kaolinite). The volcanic rock data are from Revil et al. (1996) and Revil et al. (2002).

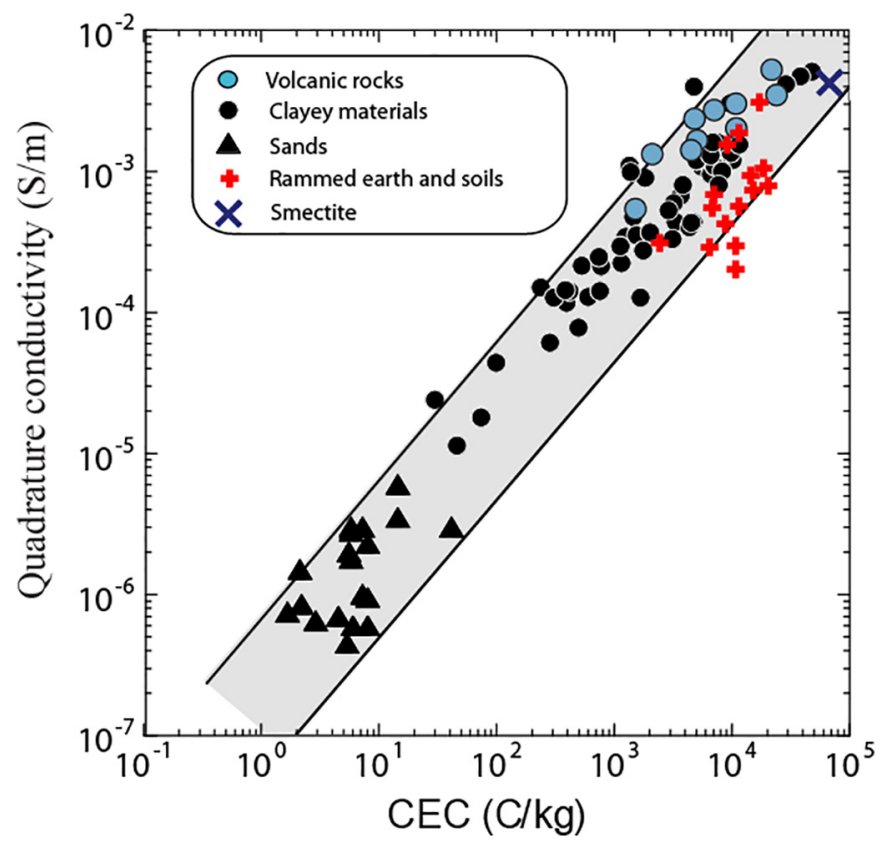

Fig. 11. Quadrature conductivity versus cation exchange capacity (CEC). The data shown in the figure are those discussed in Revil et al. (2015). Note: 1 meq $/(100 \mathrm{~g})=963.2 \mathrm{C} \mathrm{kg}^{-1}$. For porous soils and rocks, at full water saturation, the quadrature conductivity is mostly controlled by the cation exchange capacity of the material.
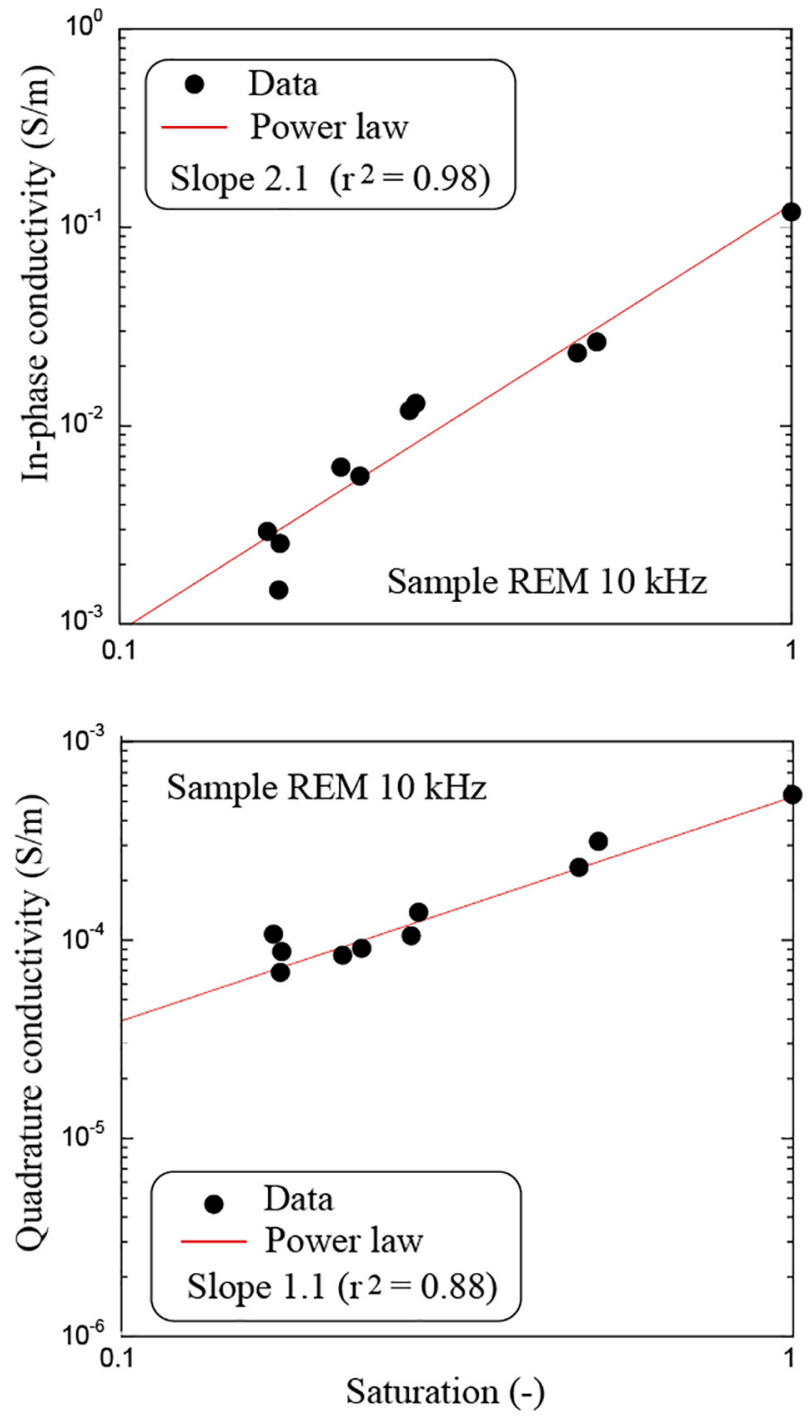

Fig. 12. In phase and quadrature conductivity as a function of saturation. The two datasets yields a consistent value of $m=2.1$ fairly consistent with $m=1.8$ obtained with Archie's law (see Fig. 7).

\section{Conclusion}

Electrical conductivity measurements of rammed earth depend on two parameters, the cation exchange capacity (CEC) of the material and its water content (assuming temperature and pore water salinity are indepdently known). This make electrical conductivity imaging an unsuitable technique to image the water content unless additional information is provided to separate the effect of the CEC and the water content. Complex conductivity (induced polarization) measurements provide such complementary information, especially normalized chargeability imaging. In order to provide a proof-of-concept of our approach, a laboratory investigation was undertaken to demonstrate the usefulness of induced polarization to fullfil this task.

The complex conductivity of soil samples and rammed earth samples has been analyzed in the frequency range $100 \mathrm{mHz}-45 \mathrm{kHz}$. The core samples used in this study have been characterized in terms of porosity and cation exchange capacity. Measurements were done at different salinities ( $\mathrm{NaCl}$ solutions) and saturation levels. These measurements are used to determine the cementation exponent $m$ of Archie's law and the dependence of the surface conductivity, the normalized chargeability, and the quadrature conductivity versus the cation exchange capacity. The measurements are all consistent with the 
predictions of the so-called dynamic Stern layer model explaining the polarization of clayey soils. These results open the door to the intrusive characterization, imaging, and monitoring of the moisture content of walls made of rammed earth. This will be the target of a future research work.

\section{Declaration of Competing Interest}

The authors declare that they have no known competing financial interests or personal relationships that could have appeared to influence the work reported in this paper.

\section{Acknowledgements}

This work is part of the ANR project VBATCH "Raw earth construction vulnerability regarding hydric conditions" funded by Agence National de la Recherche in France. We thank Egon Zimmerman for the construction of the ZEL-SIP04-V02 impedancemeter used in this work. We thank the Editor Janusz Wasowski and the two referees for their very constructive comments.

\section{References}

Abdulsamad, F., Revil, A., Soueid Ahmed, A., Coperey, A., Karaoulis, M., Nicaise, S. Peyras, L., 2019. Induced polarization tomography applied to the detection and the monitoring of leaks in embankments. Eng. Geol. 254, 89-101. https://doi.org/10. 1016/j.enggeo.2019.04.001.

Aran, D., Maul, A., Masfaraud, J.F., 2008. A spectrophotometric measurement of soil cation exchange capacity based on cobaltihexamine chloride absorbance. Compt. Rendus Geosci. 340 (12), 865-871. https://doi.org/10.1016/j.crte.2008.07.015.

Archie, G.E., 1942. The Electrical Resistivity Log as an Aid in Determining some Reservoir Characteristics. SPE-942054-G. 146. pp. 54-62. https://doi.org/10.2118/942054-G.

Baize, D., Girard, M., 1998. A Sound Reference Base for Soils: The "Référentiel Pédologique". Institut National de La Recherche Agronomique, Paris Editors.

Binley, A., Slater, L.D., Fukes, M., Cassiani, G., 2005. Relationship between spectral induced polarization and hydraulic properties of saturated and unsaturated sandstone. Water Resour. Res. 41, w12417. https://doi.org/10.1029/2005WR004202.

Binley, A., Hubbard, S.S., Huisman, J.A., Revil, A., Robinson, D.A., Singha, K., Slater, L.D., 2015. The emergence of hydrogeophysics for improved understanding of subsurface processes over multiple scales. Water Resour. Res. 51, 3837-3866. https://doi.org/ 10.1002/2015WR017016.

Bolève, A., Crespy, A., Revil, A., Janod, F., Mattiuzzo, J.L., 2007. Streaming potentials of granular media: Influence of the Dukhin and Reynolds numbers. J. Geophys. Res. 112, B08204. https://doi.org/10.1029/2006JB004673.

Börner, F.D., 1992. Complex conductivity measurements of reservoir properties. In: Proceedings of the Third European Core Analysis Symposium, Paris, pp. 359-386.

Bruno, A.W., Gallipoli, D., Salmon, N., Bruno, A.W., Gallipoli, D., Mendes, J., 2016. Briques de terre crue: procédure de compactage haute pression et influence sur les propriétés mécaniques. 33èmes Rencontres de l'AUGC, ISABTP/UPP, Anglet, 27 au 29 Mai. https://doi.org/hal-01167676.

Bui, Q.B., Morel, J.C., Reddy, B.V.V., Ghayad, W., 2009a. Durability of rammed earth walls exposed for 20 years to natural weathering. Build. Environ. 44 (5), 912-919. https://doi.org/10.1016/j.buildenv.2008.07.001.

Bui, Q.B., Morel, J.C., Hans, S., Meunier, N., 2009b. Compression behaviour of nonindustrial materials in civil engineering by three scale experiments: the case of rammed earth. Mater. Struct. 42 (8), 1101-1116. https://doi.org/10.1617/s11527 008-9446-y.

Chapman, D.L., 1913. A contribution to the theory of electrocapillarity. Philos. Mag. 25, 475-481. https://doi.org/10.1080/14786440408634187.

Chauhan, P., El Hajjar, A., Prime, N., Plé, O., 2019. Unsaturated behavior of rammed earth: experimentation towards numerical modelling. In: Construction and Building Materials. 227. pp. 116646. https://doi.org/10.1016/j.conbuildmat.2019.08.027.

Churcher, R.L., French, P.R., Shaw, J.C., Schramm, L.L., 1991. Paper SPE 21041 presented at the 1991 Int. Symp. On Oilfield Chemistry, Anaheim, February 20-22, 1991.

Ciesielski, H., Sterckeman, T., Santerne, M., Willery, J.P., 1997. Determination of cation exchange capacity and exchangeable cations in soils by means of cobalt hexamine trichloride. Effects of experimental conditions. Agronomie 17 (1), 1-7. https://doi. org/10.1051/agro:19970101.

Comparon, L., 2005. Etude expérimentale des propriétés électriques et diélectriques des matériaux argileux consolidés. PhD Thesis. Institut de Physique du Globe de Paris 400 pp.. https://hal.archives-ouvertes.fr/tel-00135855/.

Ghorbani, A., Revil, A., Coperey, A., Soueid Ahmed, A., Roque, S., Heap, M.J., et al., 2018. Complex conductivity of volcanic rocks and the geophysical mapping of alteration in volcanoes. J. Volcanol. Geotherm. Res. 357, 106-127. https://doi.org/10. 1016/j.jvolgeores.2018.04.014.

Gouy, G.L., 1910. Sur la constitution de la charge électrique à la surface d'un électrolyte. J. Phys. Theor. Appl. 9, 457-468. https://doi.org/10.1051/

jphystap:019100090045700.
Himi, M., Casado, I., Sendros, A., Lovera, R., Rivero, L., Casas, A., 2018. Assessing preferential seepage and monitoring mortar injection through an earthen dam settled over a gypsiferous substrate using combined geophysical methods. Eng. Geol. 246, 212-221. https://doi.org/10.1016/j.enggeo.2018.10.002.

Jougnot, D., Ghorbani, A., Revil, A., Leroy, P., Cosenza, P., 2010. Spectral Induced Polarization of partially saturated clay-rocks: a mechanistic approach. Geophys. J. Int. 180 (1), 210-224. https://doi.org/10.1111/j.1365-246X.2009.04426.x. 2010.

Kemna, A., Binley, A., Cassiani, G., Niederleithinger, E., Revil, A., Slater, L., Williams, K.H., Flores Orozco, A., Haegel, F.-H., Hördt, A., Kruschwitz, S., Leroux, V., Titov, K., Zimmermann, E., 2012. An overview of the spectral induced polarization method for near-surface applications. Near Surf. Geophys. 10, 453-468. https://doi.org/10. 3997/1873-0604.2012027.

Kurniawan, B., 2005. In: Louisiana State University (Ed.), Shaly Sand Interpretation Using CEC-Dependent Petrophysical Parameters, PhD Thesis. 201 pp.. https:// digitalcommons.lsu.edu/gradschool_dissertations/2384.

Lorne, B., Perrier, F., Avouac, J.-P., 1999. Streaming potential measurements. 1. Properties of the electrical double layer from crushed rock samples. J. Geophys. Res. 104 (17), 857-877. https://doi.org/10.1029/1999JB900156.

Martínez-Moreno, F.J., Delgado-Ramos, F., Galindo-Zaldívar, J., Martín-Rosales, W., López-Chicano, M., González-Castillo, L., 2018. Identification of leakage and potential areas for internal erosion combining ERT and IP techniques at the Negratín Dam left abutment (Granada, Southern Spain). Eng. Geol. 240, 74-80. https://doi.org/10. 1016/j.enggeo.2018.04.012.

Miccoli, L., Müller, U., Perrone, C., Ziegert, C., 2012. Earth block masonry, rammed earth and cob: earthen components from different construction techniques and their structural performance. In: Proc. 11th Int. Conference on the Study and Conservation of Earthen Architectural Heritage, pp. 2012.

Niroumand, H., Zain, M.F.M., Jamil, M., 2013. Assessing of critical parameters on earth architecture and earth buildings as a vernacular and sustainable architecture in various countries. Procedia Soc. Behav. Sci. 89, 248-260. 1877-0428. https://doi. org/10.1016/j.sbspro.2013.08.843.

Okay, G., Cosenza, P., Ghorbani, A., Camerlynck, C., Cabrera, J., Florsch, N., Revil, A., 2013. Characterization of macroscopic heterogeneities in clay-rocks using induced polarization: Field tests at the experimental underground research laboratory of Tournemire (Aveyron, France). Geophys. Prospect. 61, 134-152. https://doi.org/10. 1111/j.1365-2478.2012.01054.x.

Olhoeft, G.R., 1985. Low-frequency electrical properties. Geophysics 50, 2492-2503. https://doi.org/10.1190/1.1441880.

Panthulu, T.V., Krishnaiah, C., Shirke, J.M., 2001. Detection of seepage paths in earth dams using self-potential and electrical resistivity methods. Eng. Geol. 59, 281-295. https://doi.org/10.1016/S0013-7952(00)00082-X.

Revil, A., 2013a. On charge accumulation in heterogeneous porous rocks under the influence of an external electric field. Geophysics 78 (4), D271-D291. https://doi.org/ 10.1190/geo2012-0503.1.

Revil, A., 2013b. Effective conductivity and permittivity of unsaturated porous materials in the frequency range $1 \mathrm{mHz}-1 \mathrm{GHz}$. Water Resour. Res. 49, 306-327. https://doi. org/10.1029/2012WR012700.

Revil, A., Darot, M., Pezard, P.A., Becker, K., 1996. Electrical conduction in oceanic dikes, Hole 504B. In: Alt, J.C., Kinoshita, H. (Eds.), Proc. ODP Sci. Res., 148, College Station, TX (ODP), pp. 297-305.

Revil, A., Hermitte, D., Spangenberg, E., Cochémé, J.J., 2002. Electrical properties of zeolitized volcaniclastic materials. J. Geophys. Res. 107 (B8), 2168. https://doi.org/ 10.1029/2001JB000599.

Revil, A., Karaoulis, M., Johnson, T., Kemna, A., 2012. Review: some low-frequency electrical methods for subsurface characterization and monitoring in hydrogeology. Hydrogeol. J. 20 (4), 617-658. https://doi.org/10.1007/s10040-011-0819-x.

Revil, A., Kessouri, P., Torres-Verdín, C., 2014. Electrical conductivity, induced polarization, and permeability of the Fontainebleau sandstone. Geophysics 79 (5), D301-D318. https://doi.org/10.1190/GEO2014-0036.1.

Revil, A., Binley, A., Mejus, L., Kessouri, P., 2015. Predicting permeability from the characteristic relaxation time and intrinsic formation factor of complex conductivity spectra. Water Resour. Res. 51. https://doi.org/10.1002/2015WR017074.

Revil, A., Coperey, A., Shao, Z., Florsch, F., Fabricius, L.I., Deng, Y., Delsman, J.R., 2017a. Complex conductivity of soils. Water Resour. Res. 53 (8), 7121-7147. https://doi. org/10.1002/2017WR020655.

Revil, A., Le Breton, M., Niu, Q., Wallin, E., Haskins, E., Thomas, D.M., 2017b. Induced polarization of volcanic rocks. 1. Surface versus quadrature conductivity. Geophys. J. Int. 208, 826-844. https://doi.org/10.1093/gji/ggw444.

Revil, A., Le Breton, M., Niu, Q., Wallin, E., Haskins, E., Thomas, D.M., 2017c. Induced polarization of volcanic rocks. 2. Influence of pore size and permeability. Geophys. J. Int. 208, 814-825. https://doi.org/10.1093/gji/ggw382.

Rozycki, A., Ruiz Fonticiella, J.M., Cuadra, A., 2006. Detection and evaluation of horizontal fractures in earth dams using the self-potential method. Eng. Geol. 82, 145-153. https://doi.org/10.1016/j.enggeo.2005.09.013.

Schlumberger, C., 1920. Etude sur la prospection électrique du sous-sol, Gauthier-Villars, Paris. The second edition without modification is available at https://gallica.bnf.fr/ ark:/12148/bpt6k64569898.texteImage English version, translated by Sherwin F. Kelly: "Study of underground electrical prospection". Available for instance at here: https://archive.org/details/studyofundergrou00schlrich/page/n37.

Schmutz, M., Ghorbani, A., Vaudelet, P., Blondel, A., 2014. Cable arrangement to reduce electromagnetic coupling effects in spectral-induced polarization studies. Geophysics 79 (2). https://doi.org/10.1190/geo2013-0301.1.

Sogade, J.A., Scira-Scappuzzo, F., Vichabian, Y., Shi, W., Rodi, W., Lesmes, D.P., Morgan, F.D., 2006. Induced-polarization detection and mapping of contaminant plumes. Geophysics 71 (3), B75-B84.

Stern, O., 1924. Zur Theorie der elektrolytischen doppelschicht. 30. pp. 508-516. 
https://doi.org/10.1002/bbpc.192400182. 21-22.

Subrt, L., Pechac, P., 2012. Intelligent Walls as Autonomous Parts of Smart Indoor Environments. 6(8). pp. 1004-1010. https://doi.org/10.1049/iet-com.2010.0544.

Van Olphen, H., Waxman, M.H., 1958. Surface conductance of sodium bentonite in water. In: Proceedings of the Fifth National Conference, Clays and Clay Minerals, NAS-RRC Pub. 566. pp. 61-80.

Van Voorhis, G.D., Nelson, P.H., Drake, T.L., 1973. Complex resistivity spectra of porphyry copper mineralization. Geophysics 38 (1), 49-60. https://doi.org/10.1190/1. 1440333.

Vinegar, H., Waxman, M., 1984. Induced polarization of shaly sands. Geophysics 49 (8), 1267-1287. https://doi.org/10.1190/1.1441755.

Weller, A., Slater, L., Nordsiek, S., 2013. On the relationship between induced polarization and surface conductivity: implications for petrophysical interpretation of electrical measurements. Geophysics 78 (5), D315-D325. https://doi.org/10.1190/ geo2013-0076.1

Woodruff, W.F., Revil, A., Torres-Verdín, C., 2014. Laboratory determination of the complex conductivity tensor of unconventional anisotropic shales. Geophysics 79 (5), E183-E200. https://doi.org/10.1190/GEO2013-0367.1.

Zimmermann, E., Kemna, A., Berwix, J., Glaas, W., Münch, H.M., Huisman, J.A., 2008. A high-accuracy impedance spectrometer for measuring sediments with low polarizability. Meas. Sci. Technol. 19 (10), 105603. https://doi.org/10.1088/0957-0233/ 19/10/105603.

Zukoski, C.F., Saville, D.A., 1986a. The interpretation of electrokinetic measurements using a dynamic model of the Stern layer. I. The dynamic model. J. Colloid Interface Sci. 114 (1), 32-44.

Zukoski, C.F., Saville, D.A., 1986b. The interpretation of electrokinetic measurements using a dynamic model of the Stern layer. II. Comparisons between theory and experiments. J. Colloid Interface Sci. 114 (1), 45-53. 